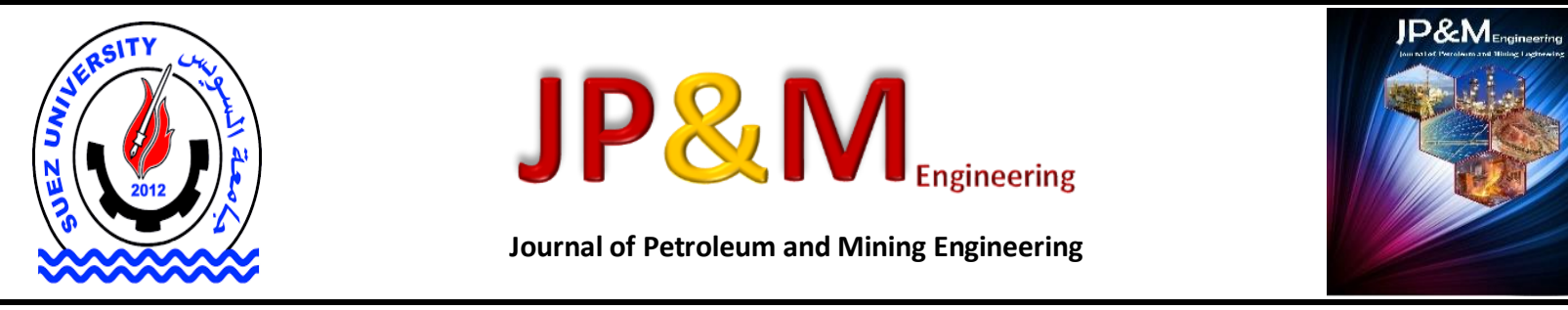

\title{
Gravel Packing Sand Control Technique, Case Study, Belayim field, Gulf of
}

\section{Suez, Egypt.}

Samir, A. ${ }^{a, *}$, Kassab, M. ${ }^{b}$, Hamed, A, ${ }^{a}$, Abbass, A. ${ }^{a}$, Salem, A. M. ${ }^{a}$

*Faculty of Petroleum and Mining Engineering, Suez University, Suez, Egypt

** Petroleum Research Institute, Cairo, Egypt

*Corresponding author e-mail: ahmed.sameer2020@yahoo.com

\section{Article Info}

Received 25 Feb. 2021

Revised 18 Apr. 2021

Accepted 9 May. 2021

\section{Keywords}

"Gravel Packing; Sand Control; Water Flooding; Sand Production".

\begin{abstract}
Sand production is always a challenge for oil production companies worldwide. Several factors can cause sand production, poor cementing material in the reservoir rock, high production rates which cause high draw down result in an unstable zone. The studied field is Belayim field consists of 105 wells; 90 of these wells are oil producing wells, 11 are water injection wells, two wells are dump flood wells, and two wells are water source wells.

The main target was to perform a gravel pack job on a high permeability water source well to deliver a planned rate of 25,000 BOPD. The study has been done for the formation, the well was considered as a critical well because of the number of challenges and because of its importance to the company in supplying the field with the injection water

After pay zone perforating, the well suffered from high losses as expected. The losses reduced by pumping several non-damaging fluid loss pills (lost circulation material) until the losses were suitable for running the gravel pack assembly in the hole. The treatment was pumped in consecutive stages of clean fluid and slurry fluid to aid in the displacement of the proppant in the well annulus and to reduce the risk of bridging.

Premium screens (6-5/8 in. with 175 micron filter) were used with a 40/60 proppant. A 5inch wash pipe was used to force most of the fluid in the slurry to remain in the casing/screen annulus to Maximize sand transport, rather than leaking off through the screen and into the screen base pipe/wash pipe annulus. The gravel pack material and the treatment chemicals was successfully pumped, covering the $500 \mathrm{ft}$ of screens and leaving excess volume of sand covering the blanks. The well was completed with ESP (electrical submersible pump) and producing 11,500 BWPD (barrel water per day).

The injection in the field resumed after being down for five months as a result from shutting down the well.
\end{abstract}

enhancing the productivity in the oil producer wells [3]. The company depends on water source wells to deliver large volumes of water to offshore platforms to be used for water injection. However, the primary challenge encountered by the company is the sand production production through sweeping the reservoir which cause increasing in the reservoir pressure, and consequently, 
problems arising from the characteristics of the formation composition, as shown in (Table 1).

Table 1 Water source well mineralogical composition

\begin{tabular}{|c|c|}
\hline Mineral & WT\% \\
\hline \hline Quartz & 60 \\
\hline Calcite & 15 \\
\hline Dolomite & 10 \\
\hline Microcline & 3 \\
\hline Plagioclase & 5 \\
\hline Orthoclase & 2 \\
\hline Kaolinite and Illite & 5 \\
\hline
\end{tabular}

The studied field is Belayim field, located in the northern part of the Gulf of Suez (Figure 1). The field was discovered in 1963, and the first production platform was installed in 1979. By this time, the reservoir pressure in the producing wells began to decline, and the production began to decrease.

Consequently, a water flooding system began in the field in April 1996. Injection rates reached up to 150,000 BWPD (barrel water per day) but has been decreasing since January 2001 as a result of reservoir management and operational issues. The reservoir primarily consists of laminated sandstone with poor vertical permeability between reservoir layers. In an offshore field with low well density, water flooding is necessary to provide greater oil sweep efficiency and to maintain reservoir pressure for all of the producing pay zone layers. All of the required water volume was supplied by water source well(s) (WSW) that were drilled and completed specifically for this purpose [1].

The Upper Cretaceous Nezzazat reservoir was discovered in 1978 during the appraisal of the underlying Nubia accumulation. The single pool of light oil is trapped in a tilted fault block. The pool is sealed by a simple toplateral fault combination. The reservoirs are fine- to medium-grained quartz arenites, deposited in coastal and fluvial environments. Most of the oil is produced from a channel in the Wata Formation. Thicknesses and reservoir properties vary considerably, both within and between the reservoir formations. The Matulla Formation has a weak aquifer drive, whereas the natural drive in the Wata Formation is solution gas.[5].

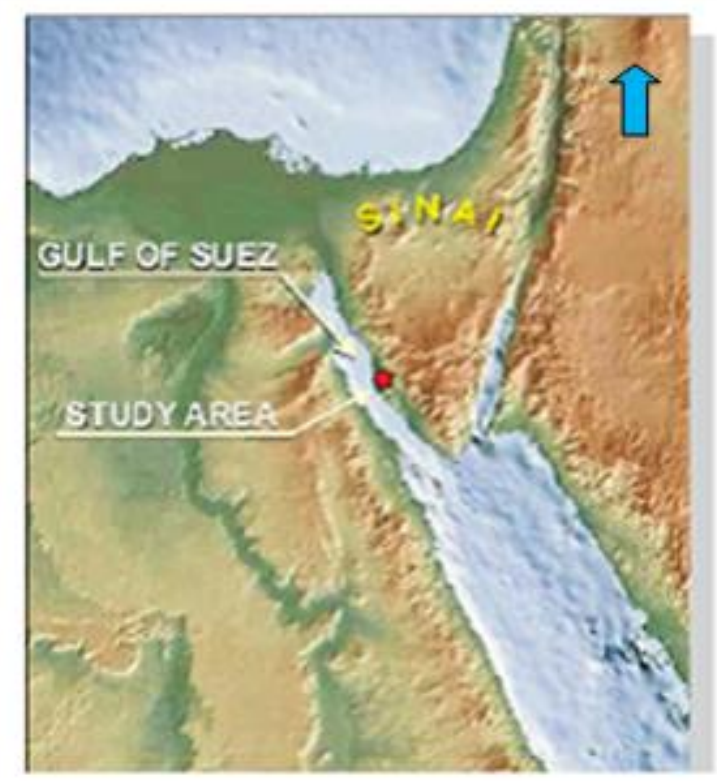

Figure 1 Location of Belayim fields on Egypt's map

\section{Geological settings}

The Gulf of Suez in Egypt has a north-northwestsouth-south east orientation and is located at the junction of the African and Arabian plates where it separates the northeast African continent from the Sinai Peninsula. It has excellent hydrocarbon potential, with the prospective sedimentary basin area measuring approximately $19,000 \mathrm{~km}^{2}$, and it is considered as the most prolific oil province rift basin in Africa and the Middle East. This basin contains more than 80 oil fields, with reserves ranging from 1350 to less than 1 million bbl, in reservoirs of Precambrian to Quaternary age. The lithostratigraphic units in the Gulf of Suez can be subdivided into three mega sequences: a prerift succession (Pre-Miocene or Paleo-zoic-Eocene), a synrift succession (Oligocene-Miocene), and apostrift succession (post-Miocene or Pliocene-Holocene). These units vary in lithology, thickness, areal distribution, depositional environment, and hydrocarbon importance. 
Geological and geo-physical data show that the northern and central Gulf of Suez consist of several narrow, elongated depositional troughs, whereas the southern part is dominated by a tilt-block terrane, containing numerous offset linear highs.

Major prerift and synrift source rocks have potential to yield oil and/or gas and are mature enough in the deep kitchens to generate hydrocarbons. Geochemical parameters, sterane distribution, and biomarker correlations are consistent with oils generated from marine source rocks. Oils in the Gulf of Suez were sourced from potential source rock intervals in the prerift succession that are typically oil prone (type I), and in places oil and gas prone (type II), orare composites of more than one type (multiple types I, II, or III for oil prone, oil and gas prone, or gas prone, respectively). The reservoirs can be classified into prerift reservoirs, such as the Precambrian granitic rocks, Paleozoic-Cretaceous Nubian sand-stones, Upper Cretaceous Nezzazat sandstones and the fractured Eocene Thebes limestone; and synrift reservoirs, such the Miocene sandstones and carbonates of the Nukhul, Rudeis, Kareem, and Belayim formations and the sandstones of South Gharib, Zeit, and post-Zeit. The majority of oil fields in the region incorporate multiple productive reservoirs. Miocene evaporates are the ultimate hydrocarbon seals, whereas the shale and dense limestones of the prerift and the synrift stratigraphic units are the primary seals. Structural, stratigraphic, and combination traps are encountered in the study area. The Gulf of Suez is the most prolific and prospective oil province in Egypt, and any open acreage, or relinquished area, will be of great in-tersest to the oil industry.

The target water production layer is a thick (+/$500 \mathrm{ft}$ ), highly permeable (2 to 10 Darcies) sandstone layer. Offset water source wells have a history of sand production at rates similar to the well's target rate of approximately 20,000 bbl/day (barrel per day). No logs were available for the pay zone to be used as a guide in the well design. Both offset wells were drilled approximately 20 years ago, and limited data about the formation description or the lower completion design basis was available. The target formation has low pressure $(1,400 \mathrm{psi}$ at $3,000 \mathrm{ft}$ subsea), and it is not capable of flowing naturally. The reservoir pressure has been confirmed to be steady over the last 20 years, despite the high-water withdrawal rate. Figure 2 shows a lithological column of Belayim field [6].

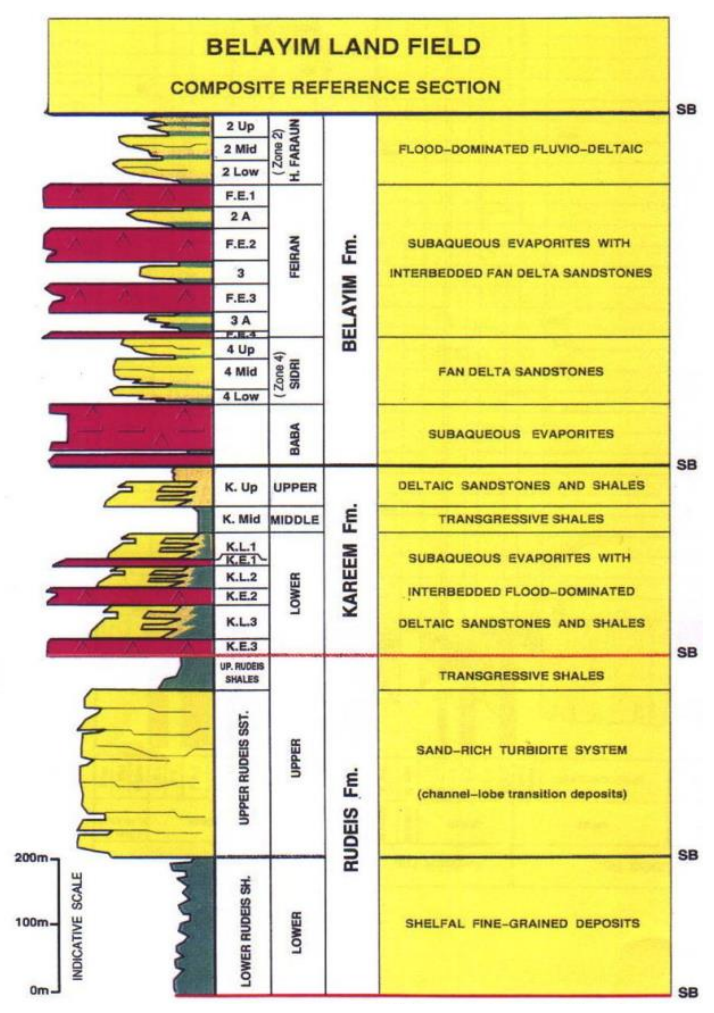

Figure 2 Belayim fields geological section

\section{Methods and techniques}

Based on the commercial study and the limited number of free slots on the offshore platform, the target well was a plug and abandonment (P\&A) well from an existing producer that has produced from a deeper zone and re-complete the well as a water source well from the shallower one. The well, as discussed, was of high importance and very challenging. Performing a gravel pack for a $500 \mathrm{ft}$ high permeability formation was not a conventional treatment to design. Many parameters were critical in the selection of this treatment, beginning with the gravel size, pumping procedures, and fluid loss control method [7].

The completion string was designed to cover the entire $500 \mathrm{ft}$ of perforations with screens and to add half their length with blanks to ensure that the screen would be covered after the proppant settled. The screens used for the gravel pack were 175 microns. The recommended screen should be 125 microns; however, because the smallest grain size for $40 / 60$ gravel is 250 micron and there is $20 \%$ safety factor, the 175 -micron 
screens can technically work and have been successful in previous jobs.

The system used for the job was a high rate water pack, which could tolerate a fracture rating of $8,820 \mathrm{psi}$, with $20 \mathrm{bbl} / \mathrm{min}$ (barrel per minute), and 60,000 lb for $20 / 40$ gravel. The gravel pack tool used was a live annulus tool with a weight-down indicator position for the circulation position. Wash pipe of 5 -inch OD (outer diameter) was used to cover the minimum ratio between the ID (internal diameter) of the screens and the OD (outer diameter) of the wash pipe to avoid bridging while pumping [8].

\subsection{Procedures and Solutions Provided}

This section includes specific information about the challenges encountered and the solutions provided. A sand sieve analysis was performed on an offset well to obtain gravel size; the analysis showed that the recommended gravel size for the treatment was $12 / 20$ [9]. Because of the high production rates of up to 25,000 BWPD in the area and the expected well production rate of +/- 15,000 BWPD; however, the design was performed with $40 / 60$ gravel size to mitigate any fine sand migration or production with this high water production rates. Table 2 shows the sand sieve analysis of an offset well [7].

Fluid loss represents a very challenging parameter when treating a long interval that has a permeability of 5 Darcie. Part of the proposed early screen out mitigation plan included the use of hydroxyethyl cellulose (HEC) as a clean low residue fluid loss pill, which could be washed by the well production or dissolved with hydrochloric acid. This plan was performed as designed and performed as a part of the proposed early screenout mitigation plan.

A special pumping technique used to avoid early screen-out, as there was a high probability risk in such a treatment that had to be mitigated for a successful treatment. The mitigation plan for the treatment included pumping pulses of clean fluid and low concentration sand-laden fluid to overcome any bridging on the perforation tunnels [10].
Table 2 Sand sieve analysis on offset well

\begin{tabular}{|c|c|c|c|c|}
\hline D40 & D50 & D90 & $\begin{array}{c}\text { Unconformi } \\
\text { ty } \\
\text { coefficient } \\
\text { (D40//D90) }\end{array}$ & $\begin{array}{c}\text { Recommend } \\
\text { ation }\end{array}$ \\
\hline 0.0145 & 0.0127 & 0.0096 & 1.5 & $\begin{array}{c}12 / 20 \text { gravel } \\
\text { with } 20 \mathrm{lb} \\
\text { screens }\end{array}$ \\
\hline
\end{tabular}

Where $D 40, D 50$ and $D 90$ are the sieve size

\subsubsection{Settling Velocity versus Maximum Rate}

\section{across the Screen}

Choking on the flow back is not the common practice when pumping a gravel pack job. The maximum flow rate across the screen is $+/-2 \mathrm{bbl} /$ minute, which could lead to proppant bridging or settling as a result of pumping with a low rate across a long high permeability zone. The process performed included increasing the pumping rate with choking to avoid damage to the lower screen. After considering the previously described challenges and the proposed mitigation plan, the treatment plan and pumping schedule was developed. The following sections provide details about the treatment pumping schedule.

In all sand control treatments, it is a common practice to pickle the tubing with acid and solvent to dissolve any solids or wax. This process avoids the risk of solids and wax getting to the screens or formation during pumping [11]. Friction tests are performed in both reverse and circulation positions to determine how much pressure is added as a result of the screens; if plugged, an acid wash is performed on the screens. This is observed by comparing the surface pressure difference between the reverse and circulation positions; the results in this job showed a minimal increase in differential pressure, indicating clear unplugged screens. Controlling fluid loss was crucial for the gravel pack treatment because of the large target zone with non-uniformity in its permeability. Consequently, controlling the fluid loss would ensure better gravel packing around the screen assembly and mitigate early screen out [12].

\subsubsection{Pumping procedure for the Gravel Pack}

\section{Treatment:}

Before pumping the gravel pack treatment, the required gravel mass needed to fill the annular volume between the screens and the perforations was 
$+/-6,400 \mathrm{lb}$. Stages of clean and sand-laden fluid were pumped simultaneously with 0.5 ppg (pound per gallon) sand concentration to fill the annulus and eliminate any bridging or screen out with the clean fluid. The treatment was divided into six sand-laden fluid stages; the last stage was $1 \mathrm{ppg}$ (pound per gallon) to maximize the length of the blanks being covered after the screen out [13].

\subsubsection{Job sequence and real time data:}

The gravel pack treatment began with a pad stage to establish injectivity with the formation and to enable adjustments of the pumping and return rates. The pad stage was followed by sand stages to begin packing the long interval down hole screens. As designed, the entire sand volume was successfully placed below the cross over port as shown by a real-time calculation. Next, the induced screen-out trial was performed by decreasing the pumping rate and increasing the sand concentration. The treatment continued until the screen- out was observed from the surface pressure (Figure 3) [10].

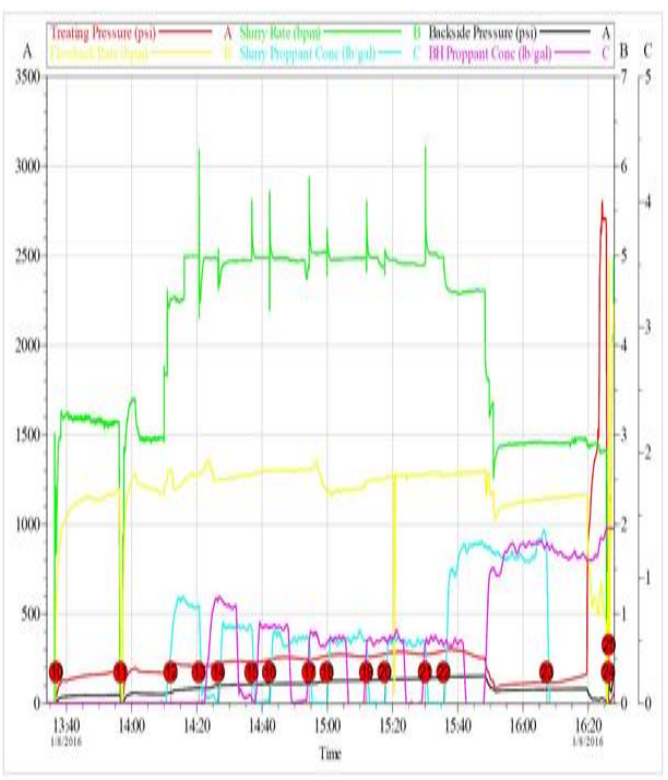

Figure $\mathbf{3}$ Gravel pack pumping treatment summary

\section{Results and Discussion}

As discussed, the studied well was of high importance and very challenging. Performing a gravel pack for a 500ft high permeability formation was not a conventional treatment to design. Many parameters were critical in the selection of this treatment, beginning with the gravel size, pumping procedures, and fluid loss control method. A gravel pack job was successfully done on the $500 \mathrm{ft}$ interval perforation with non-uniform permeability using the pulsing pumping technique of the gravel with clean carrier fluid. This technique helped in the completion of the designed gravel volume needed to pack the screens.

Some methods such as perforation vacuum or its equivalent used to after perforation to remove perforation debris, Cleaning and filtration for packing fluids (2-micron filtered), casing and tubing done before performing job. Crossover tools are used to reduce sand placement problems in high-angle holes, to promote cleanliness of packing fluid, and to minimize gravel segregation during placement.

Squeezed packing at perforations with 1 to $2 \mathrm{bbl} / \mathrm{min}$ (barrel per minute), with the rate increasing as the open area of the perforation and the hole angle increase.

The gravel pack treatment began with a pad stage to establish injectivity with the formation and to enable adjustments of the pumping and return rates. The pad stage was followed by sand stages to begin packing the long interval down hole screens. As designed, the entire sand volume was successfully placed below the crossover port as shown by a real-time calculation. Next, the induced screen-out trial was performed by decreasing the pumping rate and increasing the sand concentration. The treatment continued until the screen-out was observed from the surface pressure.

The most important information required for job design is the knowledge of formation grain size. Formation grain size may vary considerably over an interval to be gravel packed. Assuming the data are available from some source, then the design should be based on the finest segment of productive formation that is perforated so before pumping the gravel pack treatment, the required gravel mass needed to fill the annular volume between the screens and the perforations was $+/-6,400 \mathrm{lb}$. Stages of clean and sand-laden fluid were pumped simultaneously with $0.5 \mathrm{ppg}$ (pound per gallon) sand concentration to fill the annulus and eliminate any bridging or screen out with the clean fluid. The treatment was divided into six sand-laden fluid stages; the last stage was 1 ppg (pound per gallon) to maximize the length of the blanks being covered after the screen out.

The next step after completing the gravel packing job is the completion, the completion string designed to cover the $500 \mathrm{ft}$ of perforations with screens and to add 
half their length with blanks to ensure that the screen would be covered after the proppant settled. The screens used for the gravel pack were 175 microns. The recommended screen should be 125 microns; however, because the smallest grain size for $40 / 60$ gravel is 250 micron and there is $20 \%$ safety factor, the 175 -micron screens can technically work and have been successful in previous jobs.

The system used for the job was a high rate water pack, which could tolerate a fracture rating of 8,820 psi, with $20 \mathrm{bbl} / \mathrm{min}$ (barrel per minute), and $60,000 \mathrm{lb}$ for 20/40 gravel. The gravel pack tool used was a live annulus tool with a weight-down indicator position for the circulation position. Also 5-inch OD (outer diameter) wash pipe should be used to cover the minimum ratio between the ID (internal diameter) of the screens and the OD (outer diameter) of the wash pipe to avoid bridging while pumping, (complete study for the completion techniques used in the following part).

\section{The Completion string design}

The water source well is a vertically drilled well with total depth of $+/-3,300 \mathrm{ft}$. The well was completed with $4 \frac{1}{2}$-inch production tubing with an ESP (Electrical Submersible Pump), Figure 4 provides a diagram of the wellbore. The lower completion of the well includes a cased hole gravel pack treatment with $175 \mu \mathrm{m}$ screens that were packed with 40/60 natural sand. Tubing conveyed perforating guns ( TCP) were used for this well. The pay zone was perforated twice to maximize the reservoir access behind double casing.

The target well produced 11,500 bbl/day (barrel per day) versus the designed rate which is 20,000 $\mathrm{bbl} /$ day (barrel perday). The well production index (PI) was $+/-20 \%$ of the $\mathrm{PI}$ of offset producers, despite having a thicker perforated interval. Investigations confirmed that the reduced PI was attributable to the mechanical skin exerted by casing and cement, as compared to the open hole gravel pack jobs in offset producers Figure 4 [1]

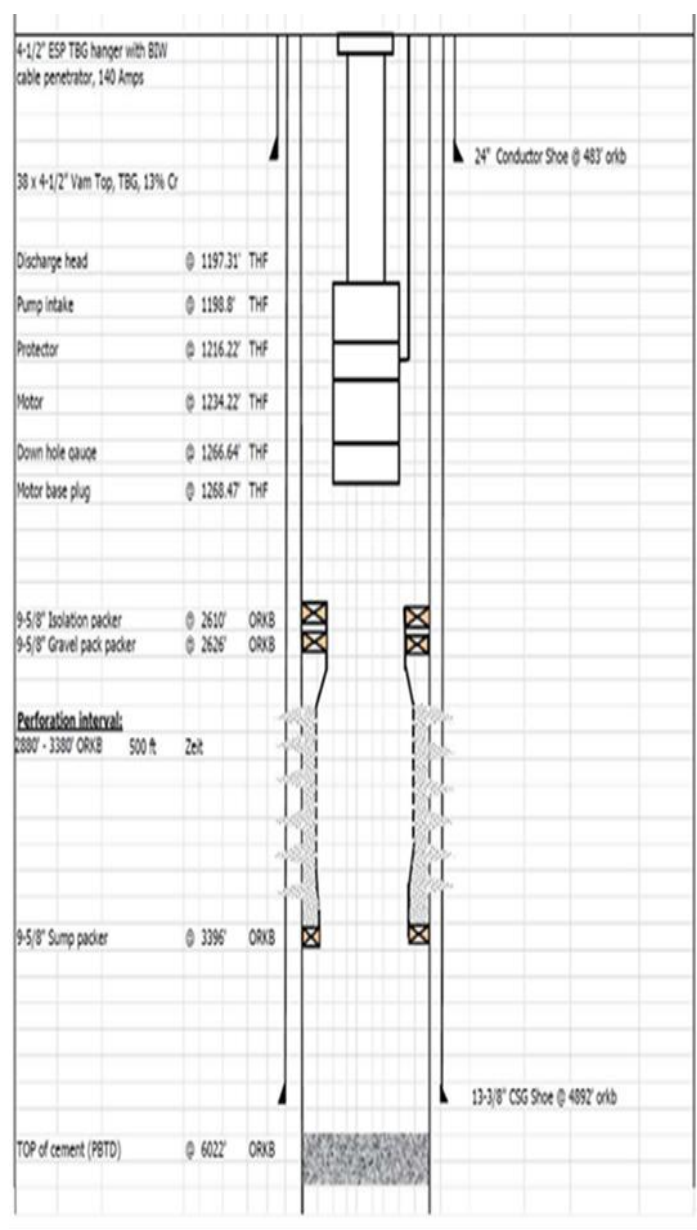

Figure 4 Wellbore diagram

\section{Conclusion}

A gravel pack job was successfully performed on the $500 \mathrm{ft}$ interval perforation with non-uniform permeability using the pulsing pumping technique of the gravel with clean carrier fluid. This technique helped in the completion of the designed gravel volume needed to pack the screens.

From the study, we can conclude the following:

[1] The ratio of pack median grain size to formation median grain size should be between 5 and 6 to minimize sand production where there is severe flow disturbance.

[2] Bridging, though satisfactory for uniform undisturbed flow, is unsatisfactory for severe (but realistic) flow conditions.

[3] Pack permeability impairment is minimized and hence production is maximized if the median-grain size ratio is 6 under severe flow conditions and with given perforations.

[4] For good results, rounded grains are better than angular grains for gravel packing.

[5] Well productivity may be enhanced with 
increasing perforation size or density.

\section{Recommendations}

[1] Perforation tunnels must be supported with gravels to avoid failure; and squeeze packing gives better

results.

[2] Before packing, perforation debris should be removed by back surging or any equivalent method.

[3] Completions string and gravel pack equipment should be cleaned and that packing fluids be compatible with the formation.

\section{References}

[1] Prouction Reports of Belayim field, 2007. "Belayim Petroleum Company Unpublished Report".

[2] Economides, M.J. and Nolte, K.G. 2000. Reservoir Stimulation, third edition, John Wiley and Sons Ltd., West Sussex, England, 6-37.

[3] Schroeder, D.E. Jr. 1987. “Gravel Pack Studies in a Full-Scale, High Pressure Wellbore Model," paper SPE 16890, SPE Annual Technical Conference and Exhibition, Dallas, 27-30 Sept.

[4] Reservoir Engineering reports of Belayim Fields, 2007. "Belayim Petroleum Company Field Unpublished Report".

[5] Said, R., 1990. The Geology of Egypt, 734 p. Balkema, Rotterdam.

[6] Geological Review of Belayim field, 2000. "Belayim Petroleum Company Field Unpublished Reports"

[7] Saucier, R.J. 1974. Considerations in Gravel Pack Design. JPT26 (02): 205-212. SPE-4030-PA.

[8] Gruesbeck, C., and Salathiel, W.M., and Echols E.E. 1979. "Design of Gravel Packs in Deviated Wellbores," JPT, 109.

[9] Ayoub, J.A., Barree, R.D., and Chu, W.C. 1997. "Evaluation of Frac and Pack Completions and Future

Outlook," paper SPE 38184, European Formation Damage Conference, The Hague, The Netherlands, 2-3 June.
[10] Maly, G.P., Robinson, J.P., and Laurie, A.M. 1974. “New Gravel-Pack Tool for Improving Pack Placement," JPT.

[11] Abou-Sayed, A.S., Zaki, K.S., Wang, G., Meng, F. and Sarfare, M.D. 2004. "Fracture Propagation and Formation Disturbance During Injection and Frac-Pack Operations in Soft Compacting Rocks," paper SPE 90656, Annual Technical Conference and Exhibition, Houston, TX, 26-29 September.

[12] Chen, Z. 2007. Horizontal Well Gravel Packing: dynamic Alpha Wave Dune Height Calculation and Its Impact on Gravel Placement Job Execution. Paper SPE 110665 presented at the 2007 SPE Annual Technical Conference and Exhibition, Anaheim, California, 1114 November. DOI: 10.2118/110665-MS.

[13] Penberthy, W.L., Bickham, K.L. and Nguyen, H.T. 1997. Gravel Placement in Horizontal Wells. Paper SPE 31147 presented at the 1996 SPE international Symposium on Formation Damage Control held in Lafayette, Louisiana, 14-15 February. DOI: 10.2118/31147-PA. 